\title{
Diferenciación de contenidos en la prensa escrita
}

\author{
Begoña GómEZ NIETO \\ Universidad de Valladolid \\ gomeznietob@hmca.uva.es
}

Recibido: 8 de abril de 2014

Aceptado: 30 de octubre de 2014

\section{Resumen}

La diferenciación de contenidos en la prensa ha sido un tema de continuo debate. Tanto el contenido informativo como el contenido publicitario están obligados a convivir en el entorno mediático actual. Esta distinción es necesaria y obligada para todos los agentes intervinientes en el proceso comunicativo: el lector, el periodista, el publicitario y el medio, que debe cumplir en cualquier caso la esencia de la profesión periodística. Este artículo analiza esta cuestión desde una doble vertiente: por una parte, los límites éticos que presenta la actividad periodística respecto a la publicidad y por lo tanto, la polémica suscitada por el papel del periodista como comunicador publicitario en muchos casos, y por otra parte, la defensa de los intereses comerciales de las empresas y organizaciones que financian esta actividad.

Palabras clave: Prensa escrita, publicidad, contenidos, ética.

\section{Differentiation of contents in the press}

\begin{abstract}
The differentiation of contents in the press has been a theme constantly discuss. Both the informative content and the advertising content are forced to coexist in the media current environment. This distinction is necessary and forced for all the agents interveners in the communicative process: the reader, the journalist, the advertising one and the media, which must fulfill in any case the essence of the journalistic profession. This article analyzes this question from a double aspect: on one side, the ethical limits that the journalistic activity presents with regard to the advertising and therefore, the polemic provoked by the paper of the journalist as advertising communicator in many cases, and on the other side, the defense of the commercial interests of the companies and organizations that finance this activity.
\end{abstract}

Keywords: Press, advertising, contents, ethics.

\section{Referencia normalizada}

GÓMEZ NIETO, Begoña (2015): "Diferenciación de contenidos en la prensa escrita". Estudios sobre el Mensaje Periodístico. Vol. 21, Núm. 2 (julio-diciembre), págs.: 1065-1080. Madrid, Servicio de Publicaciones de la Universidad Complutense.

Sumario: 1. Introducción. 2. Desarrollo. Objetivos, metodología y marco teórico; 2.1. Objetivos y metodología; 2.2. Sobre la dimensión simbólico-cultural de la publicidad; 2.3. Las distorsiones informativas. 3. El papel de los líderes de opinión en la diferenciación de contenidos. 4. La ética al servicio del contenido informativo. 5. Nuevas fórmulas de contenido publicitario para la prensa. 6. Conclusiones 7. Referencias bibliográficas.

\section{Introducción}

En el ámbito académico, los trabajos respecto a los límites de la relación entre periodismo y publicidad son relativamente escasos, más aún cuando esta discusión se plantea desde una perspectiva ética y de contenido. En efecto, los estudios sobre periodismo o publicidad se han desarrollado generalmente en forma paralela, sin abordar áreas comunes. Este hecho llama la atención, ya que se trata de un ámbito que no está exento de conflictos y donde se advierte una confusión cada vez con más frecuencia, entre el papel del periodista y el del publicista (Santibáñez, 2008). 
En su mayoría, los medios publicitarios son los grandes medios de comunicación social. La prensa, la radio, la televisión nacieron como consecuencia de la necesidad de comunicar noticias y se han revelado como instrumentos aptos para generar audiencia. Esta audiencia se pone al servicio de la publicidad, que, a su vez paga por el espacio que se le cede, contribuyendo a la financiación del medio. Ambos se necesitan y ambos se apoyan mutuamente, hasta el extremo de que no podrían concebirse los unos sin la otra y viceversa. La simbiosis es tan acentuada que resulta imposible determinar quién precedió a quién o quién, con su presencia, facilitó o hizo posible el nacimiento de quién.

Todas estas realidades irrumpieron en la sociedad a finales del siglo XIX, aunque ya venían gestándose a lo largo de décadas. Tres acontecimientos tuvieron lugar de forma casi simultánea: la revolución industrial, el nacimiento de los medios de comunicación de masas (la prensa en primer lugar) y la publicidad. Cada uno de ellos es causa y efecto de los otros dos, de forma que no pueden fijarse prioridades entre ellos ya que los tres surgieron cuando se dieron las condiciones económicas y sociales adecuadas para su nacimiento. La revolución industrial trajo como consecuencia la generalización de la fabricación en masa de productos y la consecuente necesidad de una venta también masiva. Esta necesitó - sigue necesitando- de la publicidad, sin la cual no tendría lugar. Por su parte, la publicidad necesitaba insertarse en un vehículo, el primero de los cuales fue la prensa que, a su vez, no hubiera podido sobrevivir sin el aporte económico que representaba la inserción de anuncios. Así, pues los medios de comunicación nacieron ya con sus dos vertientes, la informativa y la publicitaria (González Lobo, 1999: 73).

La prensa necesita a la publicidad para su financiación y supervivencia, y la publicidad necesita a la prensa como vehículo para llegar al gran público, por lo tanto estas dos disciplinas se necesitan y apoyan mutuamente. En líneas generales esta convivencia con el paso del tiempo y después de tantos años es un hecho normal y la diferenciación de contenidos entre publicitario e informativo parece clara, o al menos así debería ser, lo cierto es que cada vez ambos se mezclan más y la línea de diferenciación para el lector no queda nada clara.

\section{Desarrollo. Objetivos, metodología y marco teórico}

\subsection{Objetivos y metodología}

El objetivo del estudio se centra en el análisis de la relación existente entre el contenido informativo y el contenido publicitario que aparece en el medio prensa en el escenario mediático en el que se mueven estas dos disciplinas.

Esta relación se trata desde diversos ángulos: económico, social, desde el papel del periodista como comunicador y/o como soporte publicitario y cultural.

En este estudio se ha aplicado una metodología mixta: conceptual/teórica y análisis de contenido. En primer lugar se desarrolla una metodología conceptual, puesto que se ha revisado en profundidad bibliografía, artículos científicos, estudios, informes. Este planteamiento explica el uso de un análisis de contenido (Van Dijk, 2003: 149), que explica el enfoque económico, social, mediático (papel del profesional periodista) y ético en la diferenciación de contenidos en la prensa. 


\subsection{Sobre la dimensión simbólico-cultural de la publicidad}

La actividad publicitaria cumple varias funciones en el entorno social en el que se desarrolla. Una de las más importantes en su relación con la prensa es la económica: la publicidad es en muchos casos la principal vía de financiación y sin ella muchos medios estarían abocados a su extinción. Sin embargo, junto con la función económica como financiadora de los medios, la publicidad adquiere otras dimensiones. Una dimensión de negocios como mencionamos, al financiar gran parte de la industria de medios, los cuales sin su aporte económico no podrían alcanzar la masificación actual ni la variedad de sus contenidos y, por otra parte, una dimensión simbólico-cultural en cuanto establece pautas de conducta de relaciones sociales en los imaginarios colectivos ${ }^{1}$.

Baudrillard (1988: 197-198) ha señalado en su ensayo "El sistema de los objetos", que una de las primeras reivindicaciones del hombre es que se ocupen de sus deseos, de formularlos y dotarlos de imágenes. A partir de este planteamiento, la publicidad debe ser entendida como un signo de los tiempos y un actor esencial del espacio público, que entra en las costumbres y forma parte de nuestra sociedad, y también como una de sus fuentes de información indispensable respecto del estado estético y cultural de la sociedad (Moragas, 1980: 187) ${ }^{2}$. Por lo tanto, el discurso publicitario no sólo adquiere un espacio central en los medios, sino, además, una influencia determinante en la construcción de las visiones de mundo. Es así como la totalidad de nuestra cultura de masas se encuentra impregnada de sus valores que ocupan un protagonismo indiscutido en el espacio público. De ahí que si se pretendiera eliminar el discurso publicitario -o reducir su influencia- en la sociedad actual, se requeriría de un cambio de todo el entramado social y de las formas de comunicación. Para algunos autores sería como pretender entender la sociedad medieval sin considerar a la Iglesia Católica. En esta perspectiva, las agencias de publicidad tendrían una influencia moral tan importante como la Iglesia del medioevo (Rey, 2006: 67). Así como en la Edad Media la religión agrupaba a la sociedad en torno a un proyecto común, en la sociedad actual la publicidad cumpliría una función ideológica, al dotar de sentido la vida cotidiana, estableciendo parámetros de comportamiento ${ }^{3}$. La pérdida de influencia de grandes referentes como el Estado, la familia, la Iglesia, ha dejado espacio para que el discurso publicitario establezca parámetros de conducta, determine las pautas de comportamiento y dictamine los modos de comportamiento en la sociedad (Rey, 2006: 69). Como consecuencia de este protagonismo, la publicidad se ha convertido en una

1 Para E. Verón, estas pautas de relaciones sociales constituirían un modelo comunicativo comercial, a través del cual la sociedad se expresa más allá de la compra. Es decir, la publicidad jugaría un rol cultural si se consideran los efectos y el modo como ésta influye en la sociedad. E. Verón "La incertidumbre creciente". En Revista Reporte Publicidad, núm. 14 Buenos Aires, 2002.

2 Véase G. Dorfles, "Morfología e semantica della pubblicità televisiva”. En M. de Moragas, Teorías y estudios de la comunicación, Barcelona: Editorial Gustavo Gili, p. 187.

3 Esta dimensión ideológica que adquiere la publicidad la podemos entender como el relevo que hace el mensaje publicitario de las ideologías en cuanto sistema de legitimación de prácticas sociales, morales y políticas (Baudrillard, 1988:197). 
de las principales expresiones de la actual cultura de masas, y por lo tanto en una institución indispensable para su desarrollo. La publicidad puede ser considerada en gran medida como la creadora de la cultura de masas en los términos que se conoce actualmente y la que en buena parte define sus valores (Qualter, 1994: 94).

Esta relación no se convirtió automáticamente ni de inmediato en una dependencia obligada. DeFleur y Dennis (1996: 324) señalan que durante un largo período, los editores no consideraban necesario recurrir al ingreso por avisos. Diarios y revistas se financiaban mayoritariamente con el producto de la venta de los ejemplares. La Revolución Industrial cambió radicalmente la situación: "A partir del comienzo del siglo XIX en adelante, la publicidad (en Estados Unidos), creció de manera natural en la medida que se expandían los mercados y las fábricas competían por vender sus productos. A medida que avanzaba el siglo XIX, la proporción de la publicidad dentro del contenido de los periódicos y revistas fue aumentando, lo mismo que la contribución a sus ingresos"4.

Benjamin Day marcó tempranamente el nuevo rumbo. De propietario de una imprenta se convirtió en la década de 1830 en editor de un nuevo diario: The New York Sun. Este diario representaría un enorme cambio respecto de los periódicos existentes en términos de contenido, costo y público al cual se dirigía. En vez de apuntar a la elite, que podía pagar los seis centavos de costumbre, Day fijó su precio en un centavo (Wilson, 1995:99). Su idea era que la publicidad pagada podía financiar el costo no cubierto por el bajo precio de venta. El resultado fue un significativo aumento en las ventas: diez mil ejemplares al comienzo, 30 mil al cabo de cinco años. Day estableció nuevos parámetros, inaugurando la etapa de los "penny papers", en los cuales el costo de la producción se recuperaba solo en parte con el precio de venta. El ejemplo cundió, no solo en Estados Unidos. En 1836 Emile Girardin introdujo en Francia la publicidad comercial como fuente sólida de ingresos económicos del periódico, con ello el periodismo impreso se convertiría en una industria y un comercio".

La siguiente etapa era lógica: en los nuevos medios que surgen en el siglo XX, la importancia de la publicidad creció de manera acelerada. La radio y la televisión resultaron ser medios ideales para la publicidad. Como consecuencia, buena parte de la industria de medios ha logrado desarrollarse y ampliar significativamente su cobertura y oferta de contenidos. Debido a que los medios en general, pero particularmente la televisión abierta y la radio, dependen en un ciento por ciento de los ingresos publicitarios que son capaces de generar, la relación actual medios de comunicación/publicidad sería de una simbiosis entre los medios que sirven de vehículos para la difusión de anuncios y la publicidad que garantiza el financiamiento y en consecuencia, el desarrollo y la supervivencia de los medios.

4 Para DeFleur y Dennis, a pesar de que los medios habían servido desde mucho tiempo a los productores y proveedores de servicios para darse a conocer y llegar al mercado, "la publicidad no era una fuente muy importante de ingresos para los periódicos. Dependían más de los contratos de impresión con el gobierno y del precio pagado por los lectores..." 


\subsection{Las distorsiones informativas}

Diversos estudios ponen de manifiesto la variedad de contenidos híbridos que combinan información y publicidad. Se trata de mensajes que en la mayoría de los casos carecen de la debida identificación publicitaria, pero tras los cuales sí existe un pago, que es el que determina su aparición, por encima del carácter noticioso del mensaje (De Lara, 2011).

Las estrategias para sobrevivir a la pérdida de inserciones convencionales que adopta el medio se basan en la reducción del número de páginas totales del periódico y el aumento de páginas dedicadas a los contenidos sobre los que el medio posee total autonomía; en la proliferación de publirreportajes de diversos tipos y en el aumento de las distintas formas de publicidad autorreferente. Es obvio que el objetivo que lleva a poner en práctica estas estrategias se halla lejos de perseguir la calidad editorial del medio.

En cuanto al constatado incremento de los mensajes híbridos que combinan información y publicidad, cuyo objetivo no es otro que ensalzar las bondades de una marca o empresa, López afirma que gran parte de la culpa de la difícil situación que atraviesa la industria periodística del papel la poseen los propios editores, que se han cegado por las cuentas de resultados económicos, olvidando otras importantes premisas del oficio: "Muchos periódicos, canales de televisión y emisoras de radio no son otra cosa que grandes vendedores orientados a convencer a audiencias específicas de la bondad de ciertos automóviles, cosméticos, ropa o incluso políticos" (López, 2004: 22). Y, por último, la proliferación de la publicidad sobre los productos que acompañan al ejemplar refleja la preocupante situación que atraviesa el medio impreso, que busca en la promoción de productos, más o menos ajenos al diario, la tabla de salvación para alcanzar los resultados económicos marcados, sin plantearse seriamente los problemas de saturación y desvirtualización del periódico que a la larga esto puede conllevar. En palabras de Bernardo Díaz Nosty:

"El medio continuo descubre una oportunidad de futuro en su mayor independencia y en la posibilidad de erradicar las malas prácticas que llevaron a la prensa a la pérdida de credibilidad, a su alejamiento de la sociedad y a la connivencia interesada con distintas expresiones de poder" (Díaz Nosty, 2013: 123)

En un punto de referencia sin presencia de publicidad, los periódicos tratarían todas las noticias con precisión. Al ir creciendo la cantidad de anuncios, un periódico sometido al monopolio acabaría informando menos de aquellos temas sensibles al anunciante. Por decirlo de otro modo, los periódicos internalizan una parte del excedente total de los anunciantes. Como demuestran las tesis de Ellman y Germano (2009), esto no es ciencia ficción aplicada: la información sobre el calentamiento global antropogénico ha sido tergiversada u obviada en medios de comunicación estadounidenses entre 1988 y 2002. Según estudios complementarios -realizados por Boykoff y Orestes en 2004- la publicidad procedente del sector automovilístico es un factor muy relevante en la calidad de esta información, al igual que ocurre con las empresas tabaqueras. Según el estudio de estos autores "muchos eruditos en periodismo y comunicación han identificado la dependencia publicitaria como una causa seria de distorsión en el contenido de las noticias". 
Paradójicamente, una fuerte carga publicitaria puede llevar a que periódicos que compiten establezcan una precisión máxima en todos los temas, incluso en contra del interés de los anunciantes. "Los periódicos que están en competencia directa no garantizan esta precisión inmediatamente, ya que normalmente modifican sus estrategias para segmentar el mercado y no enfrentarse directamente. A pesar de esto, con suficiente cantidad de publicidad potente, el valor de atraer un lector extra es tan alto para cada periódico como para excluir esta segmentación de mercado", señala Ellman.

El estudio también evalúa un precedente histórico. A finales del siglo XIX y principios del XX se produjo en EEUU una época dorada de la prensa, la publicidad en los medios comenzó a crecer y los periódicos comenzaron a construir sus reputaciones basadas en la objetividad. La publicidad era considerada positiva, ya que reducía la dependencia de los medios con estados o partidos políticos. Sin embargo, las "distorsiones informativas" no desaparecieron. Mientras los rotativos construían su reputación mediante la precisión, los anunciantes se ganaron la suya quitando anuncios de medios que los perjudicaban.

De acuerdo con Ellman, éste no fue un hecho aislado: "La empresa más importante en cuanto a inversión publicitaria, Procter and Gamble, impuso una política en contra de anunciarse en aquellos medios cuya labor fuese en contra de su interés", en concreto, en aquellos medios que hablasen de temas como control de armas, aborto o que menospreciaran al mundo de los negocios. Para Ellman, "esto reveló el segundo resultado principal de nuestro estudio, que los grandes anunciantes con la habilidad de retirar sus anuncios evaden la anterior paradoja". Reader's Digest fue sancionado en su momento por un artículo que reflejaba una evidencia médica contra el tabaquismo. Del mismo modo, la NBC sufrió en sus propias carnes la emisión de un documental que criticaba las condiciones laborales de los trabajadores de Coca-Cola en Florida.

Los resultados de la nueva investigación son consistentes con la reciente prohibición de publicidad tabacalera en la prensa. El estudio, dice Ellman, "apoya las políticas que van más allá de regular la competición. Por ejemplo, subsidiar los medios no comerciales como la BBC y las organizaciones de medios sin ánimo de lucro pueden proporcionar alternativas competitivas que no caigan en la parcialidad que los anunciantes dictan", es decir, "reducir la competitividad en el mercado no es una respuesta sabia a la actual crisis financiera en los medios de comunicación occidentales".

\section{El papel de los líderes de opinión en la diferenciación de contenidos}

Un aspecto interesante de la relación entre los medios y la publicidad lo constituyen los denominados "líderes de opinión", muchas veces periodistas destacados de los mismos medios -o bien "rostros" del espectáculo y la farándula-, que se ofrecen como guías respecto de una adecuada conducta de consumo, siendo muy pocas veces realmente entendidos en los productos que publicitan. Para Qualter (1994:90) la lógica que subyace a esta operación estaría en que los medios de comunicación necesitan crear héroes, habitualmente efímeros, que sirven para dar contenido heroico a sus mensajes, los cuales muchas veces no tienen ninguna relación con el producto ni autoridad para avalarlo. Es más, del personaje que está avalando un producto -previo pago del anunciante-, no se espera en realidad que lo use o que sepa mucho de él. 
El periodismo nació como un servicio: alguien que tenía una información que consideraba interesante y sintió el impulso de comunicarla de manera sistemática. De este modo se estableció una diferencia con lo que había existido desde el comienzo de la historia: la información, no siempre verificada ni verificable, entregada de manera informal en un grupo, o las disposiciones de carácter oficial que la autoridad consideraba necesario comunicar por medio de edictos, pregoneros o algún tipo de letrero colocado en lugares públicos.

Por esta razón, es difícil hablar de periodismo antes de Gutenberg. Sólo a partir de la imprenta se dispuso de la tecnología necesaria para difundir la información de manera sistemática a públicos amplios y anónimos. Aunque hay indicios de algunos ejemplos anteriores, únicamente desde 1631, con La Gazette de France de Teophraste Renaudot, se puede hablar de periodismo en el mismo sentido que se emplea hasta hoy. El semanario que creó Renaudot, un médico allegado a la Corte gracias a su relación con Richelieu, se apoyaba en su conocimiento más íntimo de los entretelones del poder. Era su ventaja, pero también su peor limitación, según señala Calvet:

"El primer periódico había nacido. Pero es necesario analizar las dificultades que tuvo que superar y que también conocieron sus imitadores en el extranjero: la de abordar el gran problema de la libertad de prensa, es decir, de las relaciones entre el periódico y el poder..." (Calvet, 1958: 123)

Por lo tanto, se puede afirmar que la historia del periodismo obliga, desde su inicio, a dos lecturas paralelas: la del desarrollo tecnológico como parte sustancial del desarrollo de la industria de medios que constituyen una institución central de las sociedades modernas, y como un protagonista fundamental en el desarrollo de las sociedades democráticas y de las libertades públicas, de la lucha por lograr la máxima independencia, tanto de los poderes políticos como de los espirituales o ideológicos.

\section{La ética al servicio del contenido informativo}

Como muchos otros textos similares en buena parte del mundo, la "Carta de Deberes" de los periodistas italianos, sostiene que "los mensajes publicitarios deben ser siempre fácilmente distinguibles de los textos periodísticos". Agrega que es deber del periodista "hacer reconocible la información publicitaria y debe igualmente hacer que el público esté en condiciones de diferenciar la tarea periodística del mensaje promocional" ". No se agota aquí el catálogo de los deberes éticos de los informadores, pero es evidente que el punto resulta relevante y así se consigna en la mayoría de los códigos actualmente vigentes.

En la segunda mitad del siglo XX, se impuso el convencimiento de que el mejor camino para defender la libertad de expresión es la autorregulación. Ello explica la multiplicación de los códigos a fin de anticiparse a la imposición de normas legales coercitivas (Santibáñez, 2008). Simultáneamente, el desarrollo tecnológico plantea problemas nuevos y revive algunos de antigua data. Los nuevos son el resultado de las innovaciones que, por una parte, se manifiestan a través de la hibridación de los formatos clásicos de información periodística y de los mensajes publicitarios, y por otra,

5 Véase "Carta de Deberes de los periodistas de Italia”. En Documento de la Ordine dei Giornalisti. Publicación electrónica (http:/www.odg.it/barra/etica/etica.htm). 
las aplicaciones tecnológicas que hacen posible la invasión de los espacios privados y aun de los más íntimos de las personas. Entre los antiguos problemas está la reaparición del plagio, cometido ahora de manera que se cree indetectable, gracias a Internet y a los archivos interconectados. En una primera etapa se creyó que esta era una tentación propia de principiantes, pero algunos casos de alta connotación pública, como el de Jayson Blair, reportero de The New York Times, demuestran que puede corromper a profesionales de cualquier nivel.

La respuesta, en el plano estrictamente periodístico a estos desafíos ha sido variada. Los recursos más frecuentes van desde la definición de la línea editorial del medio, los libros (o Manuales) de Estilo, al ombudsman o Defensor del Lector, en lo que se refiere a los propios medios, y desde los Códigos de Ética a los tribunales o consejos encargados de velar por la autorregulación (Urzúa, 2005).

Bien es cierto que en ocasiones el modo de publicitar deja de informar sobre las cualidades objetivas del producto para, de acuerdo con el análisis de las tendencias, apelar a los consumidores y provocar el acto de compra, llegando en casos extremos a la utilización de técnicas de manipulación subliminal. En estos casos, la persona no percibe lo que viene "oculto" en la imagen, en la música o en la dinámica del anuncio: se le engaña con una imagen externa y otra oculta, que capta el subconsciente del consumidor. En este sentido debemos mencionar la autorregulación publicitaria, es decir la respuesta de los profesionales de la publicidad a la necesidad de regular la actividad. Se intenta disolver desde dentro los posibles casos de publicidad contraria a las normas legales y sociales. Así nace Autocontrol, cuyo propósito es apostar y defender la buena publicidad en España: una publicidad veraz, legal, honesta y leal (Autocontrol, 2014). Autocontrol es la asociación para la autorregulación de la comunicación comercial. La pertenencia a ella por parte de las agencias publicitarias y/o de comunicación tiene carácter voluntario. Es una vía de resolución extrajudicial de las reclamaciones publicitarias. Se organiza en torno a dos elementos: el Reglamento de la asociación y un Jurado que es un órgano independiente integrado por expertos. Sus objetivos son:

a. Elaborar códigos de ética publicitaria.

b. Deshacer controversias y conflictos por actuaciones publicitarias.

c. Emitir dictámenes e informes sobre cuestiones publicitarias.

d. Colaborar con organismos nacionales e internacionales para que la publicidad se ajuste a las normas.

e. Contribuir al desarrollo y perfeccionamiento de la legislación publicitaria española.

f. La actividad del jurado se apoya en: Reglamento del jurado de la asociación de Autocontrol (1 marzo 2000); Código de conducta publicitaria (14 de abril 1999); Código ético sobre la publicidad en Internet (14 de abril 1999).

El consumidor también queda protegido por leyes de la publicidad engañosa, ilícita y de cualquier tipo de práctica poco ortodoxa denunciable. La Ley 26/1984, del 19 de julio de 1984: ley general para la defensa de consumidores y usuarios es un ejemplo de ello. Cumple el mandato constitucional recogido en el artículo 51 (defensa de consumidores y usuarios). 
Relacionado con los valores éticos de la publicidad, debemos mencionar a la contrapublicidad. Representa un movimiento de crítica a la publicidad y, a través de ella, a las grandes empresas y multinacionales que la utilizan. Sus partidarios rechazan el modelo económico y las prácticas empresariales y consideran que la publicidad es un motor de consumo que muestra una realidad deformada. "Consume hasta morir" es el grupo español perteneciente a la comisión de consumo de la organización no gubernamental "Ecologistas en Acción". Difunde mensajes de consumo responsable a través de concursos, talleres, conferencias, etc. Los mensajes contrapublicitarios se difunden, generalmente, a través de canales alternativos a los medios de comunicación de masas, en las publicaciones impresas editadas por los propios colectivos $\mathrm{y}$, fundamentalmente, a través de los sitios creados en Internet, que se ha convertido en una herramienta imprescindible para la organización y difusión del activismo contrapublicitario (Pacheco, 2010).

No obstante las delimitaciones del quehacer ético de periodistas y publicistas, la realidad se ha visto sobrepasada por dos fenómenos:

1. La cuidadosa separación en géneros que había sido característica del periodismo mundial desde el siglo XIX, entró en una etapa de fronteras difusas. Aunque el último bastión han sido precisamente los medios impresos, en radio y televisión cuesta hacer la distinción entre información y opinión.

2. Como consecuencia de esta menor nitidez de las fronteras, también se hizo difusa la distinción inicial -tan marcada en la mayor parte del siglo XX-entre la tarea del periodista y del publicista, fruto de la sistematización de la enseñanza y de su consiguiente profesionalización.

Aunque en un medio escrito nos encontremos con contenido informativo y contenido publicitario y cada uno tenga su espacio, normas y función se producen fricciones que generan conflictos entre los profesionales de los medios. Ante este hecho surgen varias preguntas al respecto que contemplamos en casos concretos: por ejemplo, ¿"es admisible" que La Vanguardia edite "un monográfico titulado 'Mejores colegios de Catalunya', encartado dentro del diario, como si fuera una parte del mismo periódico, cuando se trata de un publirreportaje"? (lunes 23 de enero 2012). El suplemento, encartado como "Monográfico especial" en el centro del diario, publicitaba diferentes centros educativos de Catalunya. La pregunta es pertinente y da en el clavo de algo que el periodismo siempre ha defendido: deslindar de forma clara la información de la publicidad. En este caso, el papel y el tamaño de la publicación eran idénticos a los del diario, pero la tipografía, el color, y la estructura gráfica de las páginas mostraban diferencias. Quizás la redacción en forma de reportaje o entrevista podía crear confusión, pero por las firmas el lector descubría que los textos no eran periodísticos sino de los propios centros publicitados (Rovirosa, 2012).

Mario García ${ }^{6}$, defiende que "los lectores saben reconocer perfectamente qué es publicidad y qué información" y aboga en su libro Pure design, por una mayor imbrica-

${ }^{6}$ Gurú del diseño periodístico 
ción gráfica entre publicidad e información, aun manteniendo de forma clara su personalidad diferenciada.

Pero, ¿cómo se marcan los límites? El código deontológico del Collegi de Periodistes de Catalunya señala que "no se pueden presentar subrepticiamente las diferentes modalidades de patrocinio e información comercial como si fueran materiales informativos de las redacciones ni se deben encubrir sin que puedan ser claramente diferenciadas por los lectores". También el Libro de Estilo de La Vanguardia hace una serie de recomendaciones al respecto y advierte de los peligros de los anuncios con una composición tipográfica que pueda provocar confusión con los artículos del diario. Según el código deontológico de los periodistas, éstos no deben ejercer al mismo tiempo la profesión periodística y la publicitaria para evitar poner en compromiso la calidad de la información. Sin embargo, son muchos los periodistas que aparecen en distintos formatos anunciando productos y la publicidad cada vez está más presente en los espacios puramente informativos.

A pocos nos extraña encender la televisión y encontrarnos con periodistas de prestigio vendiendo su imagen a marcas comerciales, sin embargo, el punto 18 del código deontológico del periodista dicta lo siguiente: "A fin de no inducir a error o confusión de los usuarios, el periodista está obligado a realizar una distinción formal y rigurosa entre la información y la publicidad. Por ello, se entiende éticamente incompatible el ejercicio simultáneo de las profesiones periodísticas y publicitarias".

Una vez que los medios son absorbidos por grandes grupos de comunicación, éstos se convierten en objetos al servicio económico, es decir, en máquinas de hacer dinero y la audiencia en televisión; los oyentes en radio o los lectores de revistas y periódicos se convierten en clientes y compradores en potencia. Podemos comprobar fácilmente, cómo los medios de comunicación cada vez están más invadidos por publicidad. Este tipo de publicidad pone entre la espada y la pared al medio periodístico al completo, podemos rescatar el caso de la CBS y la tabaquera Brown \& Williamson, retratado en la película El Dilema de 1999. Cuando los medios se deben a sus anunciantes y no a su audiencia o lectores la información rigurosa y el contraste de las fuentes corren el riesgo de quedar en un segundo plano al servicio del beneficio económico (Martínez Mateo, 2014).

En el año 2011 la Asociación de la Prensa de Madrid (APM) denunciaba la creciente corriente de mezclar información con publicidad. A este respecto, Díaz Nosty, afirma que "los periodistas o supuestos periodistas que trasladan su credibilidad como prescriptores más allá de la información a un producto comercial incurren en la degradación más absoluta que puede alcanzar la profesión". Igualmente, mostró su "clara convicción de que hay que separar fuertemente información y publicidad", ya que de lo contrario los medios perderán su credibilidad. La periodista Nativel Preciado explica que "desde el momento en que un director de una cadena de televisión dice que los contenidos de su cadena son meros soportes para vender publicidad, es muy difícil luchar contra esta tendencia", y reconoce que a ella misma le han hecho ofertas para hacer anuncios publicitarios: "la última oferta que he desechado es de una marca de coñac. Es mucho dinero lo que te ofrecen, la tentación te llega".

En los últimos años se está reclamado desde la calle un periodismo más comprometido, y esto también afecta a la publicidad, lo que ha llevado a muchos medios de 
comunicación nuevos a optar por financiarse mediante las aportaciones de sus lectores o estableciendo unas líneas muy definidas entre lo que es información y publicidad. Apostar por el periodismo es decantarse por una profesión con un fuerte componente ético y que requiere un gran compromiso personal; los profesionales de la información manejan material sensible y no se debe pasar la barrera de considerar a los lectores clientes, ni anteponer el beneficio económico a la rigurosidad de las informaciones, al contraste de las fuentes y al deber de informar (Martínez Mateo, 2014).

El estilo, la manera de presentar los hechos, va en el periodismo unido a la brevedad, a la exactitud, a la precisión, y, más que a cualquier otra cosa, a la realidad. El periodista trata de conseguir la comprensión rápida y total del mensaje por parte del público y captar su atención, y ese esfuerzo ha llevado a la aparición de un lenguaje particular y, como consecuencia, a un estilo literario específico que incide en la importancia de escribir textos que se entiendan con facilidad y que sean interesantes y atractivos desde la primera línea hasta el final. Se puede afirmar que el lenguaje periodístico cuenta con las características propias de un estilo literario particular, que se distingue de otros por sus fines informativos y por la expectativa -la exigencia- del receptor del mensaje. Y debe centrarse en hacer comprensibles las informaciones (Edo, 2009: 21).

El buen periodista es un profesional atento a las necesidades del público, fiel y exacto en la descripción de los hechos y del rol que juegan cada uno de los actores activos y pasivos de esos hechos. Solamente ese buen periodismo ha sido, es y será, supongo que para siempre, la base y soporte de la calidad de los contenidos de cualquier medio de comunicación, desde el teletipo y los viejos periódicos hasta las casi infinitas posibilidades del Internet para la información noticiosa del presente y el futuro. Solamente ese buen periodismo será capaz de entregar a sus lectores información en las condiciones más adecuadas, independientemente de cuál sea el medio a través del cual la emite (Darío, 2003).

\section{Nuevas fórmulas de contenido publicitario para la prensa}

La saturación de mensajes publicitarios a la que se ven sometidos los lectores ha obligado a las organizaciones a buscar fórmulas que permitan compaginar el contenido publicitario con el informativo sin ser una molestia para el lector. Lo cierto es que la publicidad convencional ha perdido eficacia y se están empezando a imponer nuevos formatos, como las redes sociales, Youtube y, sobre todo, los anuncios en las búsquedas de Google, que suponen prácticamente el $50 \%$ del gasto por este concepto en España. Uno de los recursos más habituales es insertar contenidos en perfiles corporativos de Facebook o en Twitter de la mano de los profesionales que se conocen como community managers.

Un ejemplo de ello es el lanzamiento de una nueva plataforma publicitaria por parte de la empresa bilbaína Soda.tv, BrandCont. Lo que BrandCont ofrece es una plataforma que lanza automáticamente campañas de publicidad en contenidos periodísticos. De esta forma, no se interrumpe al usuario, si bien es cierto que tampoco se le da a conocer que, en principio, lo que está viendo es un mensaje comercial. "Es publicidad disfrazada de contenido", explica Javier G. Recuenco en Twitter. 
Muchas empresas y agencias están incorporando a especialistas en escribir para este nuevo medio, que exige una fuerte relación con los usuarios. BrandCont va más allá y ofrece insertar directamente contenidos comerciales en artículos y vídeos de medios de comunicación, disimulados como si estuvieran preparados por periodistas. Lo cierto es que el branded content existe desde hace ya muchos años. El mejor ejemplo es el que practica Bainet, la productora de Karlos Arguiñano, también asentada en Bilbao. Programas como "Bricomanía" o "En tu cocina" están patrocinados por empresas como Leroy Merlin o Fagor, que colocan estratégicamente sus productos en el decorado. Al mismo tiempo, la prensa española siempre ha estado muy mediatizada por los que marcan sus anunciantes. Por ejemplo, de todos es conocido que meterse con El Corte Inglés, no está permitido (Del Moral, 2013).

Relacionado con este aspecto, debemos mencionar un estudio realizado por Microsoft Advertising, MEC y Mindshare Worldwide que revela la diferente forma de percibir la publicidad online en los mercados maduros -Reino Unido, Francia, España, Canadá, Japón y Estados Unidos- y en los mercados emergentes como Brasil, China, Méjico, Rusia y la India. Aquellos anunciantes que busquen el marketing mix adecuado para alcanzar a los consumidores de los mercados emergentes deben tener en cuenta que el $17 \%$ de estos usuarios estaría dispuesto a ver más publicidad online que incluyera el formato vídeo. Por el contrario, el 18\% de los consumidores de mercados maduros creen se encuentran demasiadas veces ante este tipo de formatos. Los anunciantes deben ser creativos y estratégicos en su intento de alcanzar a estos usuarios a través de campañas publicitarias online (Microsoft.com, 2011).

Los consumidores de mercados maduros y emergentes están sin embargo de acuerdo en lo que se refiere a la relativa receptividad hacia los formatos "integrados" y los "intrusivos". Según este estudio, los formatos que consiguieron una puntuación más positiva estaban integrados en la aplicación que el consumidor estaba utilizando y por lo tanto los percibían como menos intrusivos. Entre los formatos que mejor captan la atención para los usuarios españoles están aquellos que son "graciosos" o en los que se ofrecen descuentos. Así, el 32\% de los encuestados españoles estaría dispuesto a interactuar con un anuncio online si éste ofreciera algo gratis a cambio; el $28 \%$ lo haría si lo encontrara divertido y el $26 \%$ si le ofreciera un descuento para un producto o servicio.

La publicidad en búsquedas y en videojuegos se percibe también como bien integrada y por lo tanto es bien recibida por los consumidores. Por el contrario, los pop ups ocuparon los puestos menos populares según las audiencias de todos los países.

El estudio muestra por lo tanto que para los anunciantes es esencial interactuar con su público objetivo de modo que la publicidad complemente la actividad online del usuario en lugar de interrumpirla negativamente. Además, una combinación de medios de pago y propios se perfila como la más popular, demostrando que ambos tipos de medios tienen cabida en el marketing mix digital.

La mayoría de los formatos publicitarios que se editan en prensa digital están elaborados para resaltar sobre el contenido, empleando recursos como colores llamativos, parpadeos, destellos etc., lo que ha provocado la aparición de la denominada 'ceguera banner' (Benway, 1998). Los usuarios, empleando estas claves visuales, han des- 
arrollado unos esquemas perceptivos que les permiten identificar la publicidad y descartarla inmediatamente como información a consultar. La solución propuesta por la mayoría de los autores es la eliminación de dichas claves, suprimiendo los elementos llamativos característicos de los diferentes formatos publicitarios y haciéndolos más parecidos a los contenidos. Para que esta estrategia tenga éxito, los formatos deben aparecer identificados como publicidad para que el internauta no se sienta engañado (Manchón, 2002).

El cerebro humano elimina todos aquellos obstáculos que nos impiden alcanzar los objetivos propuestos. En este sentido, la información que realmente interesa a los internautas es texto acompañado de imágenes, sonidos..., pero sobre todo es información textual. La mayoría de los formatos publicitarios en prensa digital son gráficos; por tanto, si el cerebro elimina los obstáculos para alcanzar sus objetivos y éstos son obtener información, el usuario irá directamente a la misma, pasando por alto cualquier aclaración no textual que, sobre todo, no haya solicitado. De estas investigaciones se deduce que los principales problemas de la publicidad en prensa digital son la falta de integración entre publicidad y contenidos, el predominio de formatos de naturaleza gráfica y el empleo de mensajes que apelan a las emociones del consumidor (Albuin, 2011).

Un elemento que es necesario considerar, que permite comprender al menos en parte lo anterior, lo constituye el creciente proceso de hibridación que afecta a los formatos clásicos del periodismo y la publicidad. Este proceso, que se ha visto acelerado por el fuerte desarrollo de las tecnologías digitales, ha contribuido a que las diferencias sean aún más difíciles de identificar. Esta hibridación confunde los límites que permiten definir dónde termina el quehacer periodístico y dónde empieza el publicitario, lo cual obviamente demanda nuevas competencias conceptuales para un análisis crítico de ambas disciplinas.

\section{Conclusiones}

La publicidad, a través de la promoción de determinados productos y servicios, cumple un rol fundamental en el desarrollo y la supervivencia económica de los medios de comunicación. Desde esta perspectiva, la publicidad constituye una garantía de libertad de expresión y en definitiva del funcionamiento democrático de una sociedad.

Sin embargo, es posible advertir riesgos no menores para un adecuado ejercicio de la libertad de información cuando, por ejemplo, los participantes en un programa de información y de discusión de temas públicos, donde lo central es el ejercicio de la crítica informada, se desdoblan e intentan convencer a su audiencia de las ventajas de un determinado producto o servicio, sin reserva alguna, simplemente apelando a su "credibilidad" en cuanto "rostros". Coincidiendo con Qualter (1994: 197), creemos que es peligroso aceptar ese desdoblamiento como algo normal. Esta actitud del panelista (llámese periodista, abogado, sociólogo, etc.) que promociona un producto como un tema supuestamente de interés nacional, degrada las facultades críticas al sustituir su pensamiento por eslóganes publicitarios escritos por otros, y reduciendo las necesidades de la audiencia a simples cuestiones que pueden resolverse con una compra. Por lo tanto, no puede ser considerada como una información adecuada y correcta en 
el contexto de un programa informativo o de discusión. Esto podría llevar a pensar que programas referidos a temas de interés nacional no constituyen fines en sí mismos, sino que son solamente medios para conseguir objetivos comerciales. De esta forma, y siguiendo la perspectiva de Habermas, los medios en este caso al estar sometidos a criterios comerciales, es decir bajo una "racionalidad instrumental", no ofrecen un marco adecuado para la discusión democrática.

Es cierto que existe más de un rasgo en común entre el periodismo y la publicidad. Ambos buscan interesar a las audiencias, se difunden en los medios masivos, proponen asuntos de interés y actualidad, forman parte del negocio comunicacional. Pero evidentemente no son lo mismo. El periodismo pretende dar a conocer acontecimientos y ofrecer elementos para entenderlos. Su agenda está dictada -hipotéticamente, al menos- por la actualidad y el interés público. La publicidad, promueve productos o instituciones. A diferencia del periodismo no muestra la mayor cantidad de facetas posibles de un acontecimiento sino únicamente las más favorables a esos productos o instituciones cuya aceptación trata de inducir.

Periodismo y publicidad se desenvuelven en el espacio público contemporáneo pero tienen diferencias muy claras. Cuando se confunden, o cuando una aparece disfrazada del otro, estamos ante un engaño a los televidentes, radioescuchas o lectores (Trejo, 2005), por lo que la diferenciación de contenidos se convierte ahora más que nunca en un hecho necesario e imprescindible.

\section{Referencias bibliográficas}

ALBUIN VENCES, Natalia (2011): "La integración y la información. Claves de la eficacia publicitaria en prensa digital". Telos, $\mathrm{n}^{\circ} 83$. Disponible en: http://telos.fundaciontelefonica.com/DYC/TELOS/NMEROSANTERIORES/Nmeros8095/Detal leAnteriores_83TELOS_ANALISIS_Laintegracionylainformacion/seccion $=1268 \&$ idioma $=$ es_ES $\&$ id $=2010051017160001 \&$ activo $=6$. do $[$ Consulta: $1 \mathrm{de}$ abril 2014].

AUTOCONTROL.ES (2014). Disponible en: http://www.autocontrol.es/pdfs /Cod_conducta_publicitaria.pdf [Consulta: 28 de febrero de 2014]

BAUDRILlARD, Jean (1988): El Sistema de los Objetos. México DF, Siglo XXI Editores.

BENWAY, Jan \& LANE, David (1998): "Banner Blindness: Web Searchers Often Miss 'Obvious Links"'. Disponible en: http://www.Internettg.org/newsletter /dec98/banner_blindness.html [Consulta: 19 de enero de 2013]

CALVET, Henri (1958): La Presse Contemporaine. Paris, Ed. Paris.

DARÍO BUITRÓN, Rubén (2003): "Seis reflexiones sobre periodismo impreso y periodismo digital". Ponencia presentada en el Seminario Internacional de Periodismo Digital, organizada por CIESPAL, Quito 24-28 noviembre 2003. Disponible en: http://www.saladeprensa.org/art606.htm [Consulta: 27 de marzo de 2014]

DEFLEUR, Melvin y DENNIS, Everette (1996): Understanding Mass Communication. Boston, Houghton Mifflin Company. 
DE LARA GONZÁLEZ, Alicia (2011): "El peso del contenido publicitario en la prensa alicantina: al caso del Diario Información y La verdad". Revista Mediterránea de Comunicación, año 2, 1-14. Disponible en: http://www.rmedcom.org /2011/1104/1104deLara.html [Consulta: 18 de marzo de 2014]

DEL MORAL, José (2013): "Branded content: contenido con publicidad o publicidad disfrazada?". Disponible en: http://gananzia.com/branded-content-contenido-conpublicidad-o-publicidad-disfrazada [Consulta: 27 de marzo de 2014].

DÍAZ NOSTY, Bernardo (2000): "La prensa escribe su futuro", en suplemento Sur 2000 del diario Sur, publicado el 3 de octubre.

DÍAZ NOSTY, Bernardo (2013): La prensa en el nuevo ecosistema informativo iQue paren las rotativas!. Madrid, Fundación Telefónica y Editorial Ariel.

DORFLES, Gillo (1985): "Morfología e semantica della pubblicità televisiva". En MORAGAS, Miquel de: Teorías de la comunicación. Barcelona, Gustavo Gili.

EDO, Concha (2009): Periodismo informativo e interpretativo. El impacto de Internet en la noticia, las fuentes y los géneros. Sevilla, Comunicación Social ediciones y publicaciones.

ELLMAN, Matthew y GERMANO, Fabrizio (2009): "What do the papers sell? A model of advertising and media bias". The Economic Journal. num. 119, 680-704. Disponible en: http://www.agenciasinc.es/Noticias/La-publicidad-en-prensa-puedeafectar-a-la-calidad-de-la-informacion [Consulta: 27 de marzo de 2014].

GONZÁLEZ LOBO, Ma Ángeles y CARRERO LÓPEZ, Enrique (1999): Manual de planificación de medios. Madrid, ESIC.

LÓPEZ LÓPEZ, Manuel (2004): Nuevas competencias para la prensa del siglo XXI. Barcelona, Paidós.

MANCHÓN, Eduardo (2003): "Ceguera a los banners, cómo se produce este fenómeno psicológico". Disponible en: http://www.alzado.org/articulo.php?id_art=90. [Consulta: 4 de abril de 2014]

MARTÍNEZ MATEO, Laura (2014): "Periodismo y Publicidad, ¿dónde está el límite?". Disponible en: http://www.lahuelladigital.com/periodismo-y-publicidaddonde-esta-el-limite/ [Consulta: 26 de marzo de 2014].

MICROSOFT.COM (2011): "Los formatos publicitarios integrados en el contenido son los más populares entre los usuarios". Disponible en: https://www.microsoft.com/spain/prensa/noticia.aspx?infoid=/2011/04/n012-publicidad-integradacontenido [Consulta: 19 de febrero de 2014].

MORAGAS, Miquel de (1980): Teorías y estudios de la comunicación. Barcelona, Gustavo Gili.

PACHECO, Marta (2010): “La contrapublicidad como herramienta para la educación mediática". Disponible en: http://www.educacionmediatica.es/comunicaciones /Eje\%202/Marta\%20Pacheco\%20Rueda.pdf [Consulta: 1 de marzo de 2014].

QUALTER, Terence H. (1994): Publicidad y democracia en la sociedad de masas. Barcelona, Paidós. 
REY, Juan (2006): “Publicidad y religión”. Trípodos núm. 18. Barcelona, Universidad Ramón Llull.

ROVIROSA, Joseph (2012): "Periodismo y publicidad". Disponible en: http://www.lavanguardia.com/opinion/articulos/20120205/54249164906/periodismo-y-publicidad.html [Consulta: 26 de marzo de 2014].

SANTIBÁÑEZ, Abraham M. y VERGARA, Enrique L. (2008): "Periodismo y publicidad: claves y ambigüedades de una relación promiscua". Revista Universum, núm. 23 Vol. 1, 248-267. Disponible en: http://www.scielo.cl/scielo.php ?script=sci_arttext\&pid=S0718-23762008000100012 [Consulta: 26 de marzo de 2014].

TREJO DELARBRE, Raúl (2005): "Periodismo y propaganda". Disponible en: http://mediocracia.wordpress.com/2005/12/15/periodismo-y-propaganda/ [Consulta: 1 de abril de 2014].

URZÚA, Manuel (2005): "La conciencia del profesional: un primer sistema de control ético". En I Encuentro de Profesores de Ética Periodística. Santiago de Chile, Colegio de Periodistas de Chile.

VAN DIJK, Teun A. (2003): "La multidisciplinaridad del análisis crítico del discurso: un alegato a favor de la diversidad". In WODAK Ruth \& Meyer, Michael (eds.): Métodos de análisis crítico del discurso. Barcelona, Gedisa.

VERÓN, Eliseo (2002): "La incertidumbre creciente”. En Revista Reporte Publicidad, núm. 14 Buenos Aires.

WILSON, James Ross (1995): Mass Media. Mass Culture. An Introduction. London, McGraw-Hill. 